\title{
Mulheres, direitos políticos, gênero e feminismo*
}

\author{
Jussara Reis Prá**
}

\section{Resumo}

Este artigo examina os direitos políticos das mulheres na história recente da América Latina, focalizando os quatro países da região que elegeram mulheres presidentes a partir de meados dos anos 2000 - Argentina, Brasil, Chile e Costa Rica. O estudo reflete sobre os avanços e os desafios na esfera da participação $e$ da representação política feminina, com base em estudos e pesquisas feministas sobre gênero e política e nas recomendações do Comitê de monitoramento da Convenção sobre a Eliminação de todas as Formas de Discriminação contra a Mulher aos países examinados.

Palavras-chave: Feminismo, Gênero, Direitos Políticos, Monitoramento.

\footnotetext{
* Recebido para publicação em 10 de agosto de 2014, aceito em 3 de outubro de 2014.

** Professora do Programa de Pós-Graduação em Ciência Política da Universidade Federal do Rio Grande do Sul - UFRGS. jussarapra@terra.com.br
} 
170 Mulheres, direitos políticos, gênero e feminismo

Women's Political Rights, Gender and Feminism

\begin{abstract}
This paper discusses the political rights of women in the recent history of Latin America in countries that have elected women presidents in the 2000s: Argentina, Brazil, Chile and Costa Rica. The study examines advances and challenges in political participation and representation of women based on studies and feminist research on gender and politics, as well as at the recommendations of the Committee of the Convention on the Elimination of All Forms of Discrimination against Women to the countries examined.
\end{abstract}

Key Words: Feminism, Gender, Political Rights, Monitoring. 
O compromisso de promover e garantir os direitos das mulheres nos ordenamentos jurídico e político dos Estados democráticos é eixo central da agenda feminista. Dos pontos de vista prático e teórico essa agenda realça o problema da subordinação feminina. Desde o(s) feminismo(s), a identificação da exclusão e da discriminação das mulheres ampliou o horizonte sobre o tema. Tal dinâmica sedimentou-se nas lutas pelo voto em séculos passados e desde os anos 1970 reverbera debates e ações contra os déficits da cidadania feminina.

A difusão de um feminismo de alcance internacional fomentou a defesa dos direitos humanos das mulheres $e$ a sua transposição para cenários regionais e nacionais. A almejada igualdade entre os sexos estimou reconhecer as mulheres em um sistema universal de promoção e proteção dos direitos humanos a partir da Carta das Nações Unidas (1945) e da Declaração Universal dos Direitos Humanos (1948). Desde a carta de 1945, o fito de respeitar e garantir os direitos humanos das mulheres integra um conjunto de normativas internacionais, delas sobressaindo a Convenção sobre a Eliminação de Todas as Formas de Discriminação contra a Mulher (CEDAW, da sigla em inglês), de 1979.

No domínio dessa Convenção, os princípios da não discriminação e da igualdade de direitos fundamentam um amplo programa de ação para as mulheres. No plano político, foco deste artigo, a CEDAW, doravante Convenção da Mulher (Pimentel. 2008), compromete seus signatários a empreender os esforços necessários para garantir a elas o direito de votar, de serem eleitas ou indicadas a cargos políticos. Para tanto, é prevista a adoção de medidas especiais temporárias (ações afirmativas) para acelerar a igualdade de facto entre homens e mulheres - posição reforçada em documentos de conferências mundiais sobre mulheres, a exemplo das Estratégias de Nairóbi (1985) e da Plataforma de Ação de Beijing (1995). Em Beijing, é reiterada a meta de alcançar cotas de $30 \%$ de representação parlamentar feminina, proporção considerada a mínima necessária para formar uma "massa crítica" capaz de incidir em decisões políticas (Dahlerup, 1999). 
Junto à proposta das cotas, o tema da paridade de gênero emerge em contextos regionais sob o marco da democracia paritária. Na Europa, o texto da Declaração de Atenas (1992) propõe o desfrute pleno e igualitário da cidadania por meio de uma representação equilibrada de mulheres e homens na política (Cobo, 2002). Na América Latina, o propósito da paridade de gênero é registrado no Consenso de Quito (2007) e reafirmado nos Consensos de Brasília (2010) e de Santo Domingo (2013). O último, além de "reiterar os compromissos com a paridade, assinalou a importância de fortalecer mecanismos de observação dos processos eleitorais desde uma perspectiva de gênero" (Llanos, 2014:14). Textos dessa índole oferecem insumos aos Estados nacionais na definição de diretrizes e pautas para a incorporação das mulheres à vida pública e política. Ao lado deles, a Convenção da Mulher, além de contundente nesse imperativo, insta seus signatários a adoção das medidas necessárias para garantir a igualdade substantiva entre mulheres e homens.

Nesse marco, o órgão de supervisão da implantação da Convenção, o Comitê CEDAW, revela-se fonte e mecanismo dessa igualdade ao monitorar os avanços das mulheres em âmbito global (Pimentel, 2008; Bareiro; Torres, 2009). Processo no qual a interlocução periódica de integrantes do Comitê com representantes da sociedade e de cada Estado-parte resulta na formulação de Observações Finais sobre vários aspectos da situação das mulheres (Pimentel, 2012). Tais observações expõem dados positivos, mas também as debilidades de cada país, entre elas, as falhas de seus sistemas políticos em propiciar a igualdade na representação de mulheres e homens.

A partir do exposto, este artigo traz ao debate a questão dos direitos políticos das mulheres na história recente da América Latina. A abordagem contempla os quatro países da região que elegeram mulheres presidentes a partir de meados dos anos 2000 Argentina, Brasil, Chile e Costa Rica. A aproximação desses casos, para além do ineditismo da eleição de quatro mulheres com mandatos próximos e do retorno de duas delas ao comando do seu país, revela variações importantes quanto ao acesso das 
mulheres a postos de poder, adiante discutidas. Consoante aos países abordados interessa refletir sobre os avanços $e$ os desafios na esfera da participação e da representação política feminina, tendo em vista as barreiras à concretização dos direitos políticos das mulheres.

A reflexão proposta se inscreve na área da Ciência Política, subsidiada por aportes teóricos de estudos feministas sobre gênero $e$ política. No plano empírico, a abordagem prioriza as Observações Finais do Comitê de monitoramento da Convenção da Mulher sobre vida pública e política, endereçadas aos países em estudo entre 2010 e 2012. Ao que se soma a apreciação de dados da participação e da representação política das mulheres $e$ de iniciativas recentes de reformas legislativas na matéria. Por esse caminho, se busca identificar as nuances da participação e da representação política femininas em países que elegeram $e$ reelegeram mulheres para a Presidência da República. Assim, estima-se somar este estudo a outros interessados em explorar a realidade da relação gênero e política e, em refletir sobre medidas $e$ ações voltadas a garantir a igualdade substantiva de mulheres $e$ homens na esfera pública e política.

A exposição inicia pela revisão de elementos conceituais dos aportes feministas e de gênero à formatação de pactos de defesa dos direitos humanos das mulheres, a exemplo da Convenção da Mulher e de seu organismo de monitoramento. Na sequência da apresentação, abordam-se questões relativas aos direitos políticos das mulheres, priorizando as Observações Finais (Concluding Observations) do Comitê CEDAW emitidas aos quatro países examinados. As reflexões finais sumarizam os avanços $e$ as tensões de um processo inconcluso para o reconhecimento dos direitos políticos das mulheres.

\section{Aportes feministas e de gênero à Convenção da Mulher}

Quando se trata dos direitos políticos das mulheres é imprescindível empregar gênero como categoria analítica para chegar "à compreensão da desigualdade em campos que foram 
considerados neutros, particularmente no âmbito da filosofia, da ciência política e das ideias que inspiram os princípios democráticos e a governabilidade" (CEPAL, 2008:5). O emprego do conceito de gênero na análise política parte da constatação do status subordinado das mulheres ao longo da história (Faccio, 1999) e remete ao processo de construção das relações de poder entre os sexos (Scott, 1990). O conceito também reporta às bases patriarcais de poder nos domínios da vida pública e privada; âmbitos nos quais sistemas de crenças e ideologias delimitam direitos, deveres e condutas para cada sexo, legitimam a ordem social estabelecida e justificam a supremacia dos homens e do masculino (Puleo, 2004). Assim, o termo expressa

$$
\begin{aligned}
& \text { tanto o conjunto de características e comportamentos, } \\
& \text { como os papéis, funções e valores impostos } \\
& \text { dicotomicamente a cada sexo através de processos de } \\
& \text { socialização, mantidos e reforçados pela ideologia e por } \\
& \text { instituições patriarcais (Faccio, 1999:13). }
\end{aligned}
$$

Tal leitura permite identificar as assimetrias das relações de poder e evidenciar a construção social das diferenças entre masculino e feminino (Amâncio, 1998). A mesma leitura oportuniza questionar as matrizes histórico-culturais da subordinação feminina, presentes em estruturas sociais, instituições, comportamentos, crenças e valores (Scott, 1990). Subordinação que vai do privado ao público e é evidenciada por discriminações que podem expressar tanto a violência de gênero quanto a subrepresentação feminina na política. A partir desse enfoque é possível identificar as dificuldades das mulheres para o exercício pleno de seus direitos políticos e, ao mesmo tempo, incidir sobre elas. Em suma, com esse olhar é possível apreender "os obstáculos que limitam ou impedem o pleno exercício dos direitos políticos das mulheres, $e$ os desafios que representa sua eliminação" (Lavalle, 2010:52); motivo pelo qual os feminismos são permanentemente desafiados a buscar estratégias para assegurar que "os direitos de cidadania das mulheres $e$ as condições para o 
seu exercício constituam questões centrais de democracia, e não apenas questões das mulheres" (Pitanguy e Miranda, 2006:31).

Com esse aporte, organizações feministas e de mulheres construíram uma história de mobilizações junto à Organização das Nações Unidas (ONU) que beira cinco decênios. Tal protagonismo, materializado em negociações de alcance global e local, qualifica a defesa da cidadania feminina e impinge a compreensão das mulheres enquanto sujeitos de direitos e prioridade de ação pública e política (Varela, 2014). Esse entendimento se vê registrado na redação de planos, acordos e pactos globais, oriundos de conferências e convenções de temas gerais ou sobre mulheres. A noção de cidadania é redefinida nesse contexto, por parâmetros normativos internacionais, corroborando reivindicações feministas e, em decorrência, a formulação de leis e de políticas públicas de gênero.

A partir da legitimidade conferida aos aportes de gênero, a ONU valida a perspectiva feminista "como categoria descritiva da situação das mulheres. Mais ainda, exige que os Estados a integrem em todas as políticas e programas, assim como na legislação" (Faccio, 1999:15). Nesse sentido, a inclusão dos aportes de gênero é definida como estratégia para transformar interesses e experiências de mulheres e homens em "uma dimensão integral do desenho, implementação, monitoramento e avaliação de políticas e programas em todas as esferas da atividade humana" (Faccio, 1999:15).

A presente intervenção parte desse entendimento a fim de enfatizar a importância da Convenção CEDAW para monitorar o desenvolvimento dos direitos políticos das mulheres. Seguindo Teresa Valdés (2013), considera-se que a Convenção da Mulher constitui "uma ferramenta para os governos, porém, sobretudo, para as organizações e movimentos de mulheres e feministas que lutam pela construção de uma ordem igualitária e não discriminatória" (Valdés, 2013:172). Por conseguinte, como diz a autora, além da legitimidade que esse instrumento confere à luta das mulheres, ele também propicia o exercício do controle da cidadania em planos nacional e internacional. 
Os textos da Convenção relacionam as formas de discriminação contra a mulher, não se atendo apenas em definilas, vez que requerem de seus Estados-Partes a implementação de todas as medidas cabíveis para superá-las. Nesse sentido, a ênfase na adoção de ações afirmativas (cotas) responde ao imperativo de erradicar a desigualdade entre mulheres e homens. Para tal, fundamenta-se na conexão entre igualdade e respeito aos direitos humanos desde a perspectiva de gênero. Assim sendo, ela reflete uma construção teórica e também política ao forjar uma agenda endereçada a garantir, promover e proteger os direitos das mulheres.

Quanto à abrangência legal, a Convenção da Mulher, somada a seu Protocolo Facultativo (1999), "é o instrumento jurídico por excelência para assegurar a igualdade entre mulheres e homens" (Durán, 2005:49). O aspecto jurídico confere força de lei à Convenção enquanto acordo vinculante entre Estados, submetendo seus signatários ao Direito Internacional (Pimentel, 2008). Dito de outro modo, a adesão a um "instrumento jurídico internacional" compromete os Estados a garantir o exercício e o desfrute dos direitos estabelecidos na Convenção. Ao mesmo tempo, esse tipo de compromisso obriga os Estados pactuantes a prestar contas das medidas adotadas para aplicar a Convenção (Piovesan, 2006).

A verificação desse acordo, como antes mencionado, é função do Comitê de monitoramento à CEDAW. ${ }^{1}$ Este organismo, integrado por 23 especialistas na área de competência da Convenção, monitora "o exercício efetivo dos direitos das mulheres nos Estados-Partes da Convenção" (Pimentel, 2008:19). O material por ele examinado abarca, a cada quatro anos, relatórios periódicos dos Estados sobre a situação da mulher $e$

${ }^{1}$ O Comitê, criado para examinar os progressos dos países signatários na aplicação da Convenção, teve suas funções e responsabilidade ampliadas pelo Protocolo Facultativo à CEDAW (1999). O Comitê é formado por 23 integrantes independentes (experts), com mandatos eletivos de quatro anos. Para uma visão detalhada sobre as atribuições e o funcionamento do Comitê, ver Silvia Pimentel (2008). 
documentos alternativos (relatórios sombra) de organizações da sociedade civil, em geral feministas (Szwako, 2010). A apropriação dessas informações e o "diálogo construtivo" com os EstadosPartes subsidiam o Comitê na elaboração das Observações Finais enviadas aos países de origem. Nessas pautas são comuns recomendações sugerindo a mudança de leis destoantes à Convenção; a elaboração de novas leis; e a adoção de ações $e$ medidas para promover a igualdade entre homens $e$ mulheres. Ainda sobre a atuação daquele órgão, é "imprescindível dizer que o Comitê busca integrar, em seu trabalho, toda a normativa internacional de proteção aos direitos humanos, pois estes são universais, indivisíveis e interdependentes" (Pimentel, 2008:66). Como esclarece Silvia Pimentel, representante brasileira no Comitê CEDAW e sua atual presidenta:

[...] todo o trabalho do Comitê se realiza com base na Convenção CEDAW e em suas Recomendações Gerais, bem como nos princípios das Declarações e plataformas de ação das Conferências Mundiais da ONU, muito especialmente, Viena/93 (Direitos Humanos), Cairo/94 (População e Desenvolvimento), Beijin/95 (Mulher - Paz, Igualdade e Desenvolvimento) e Durban/2001 (Conferência Mundial contra o Racismo, a Discriminação Racial, a Xenofobia e Formas Correlatas de Intolerância) (Pimentel, 2008:66).

Por esse prisma, a proteção dos direitos políticos das mulheres inscreve-se na Convenção da Mulher. Para tanto, os diferentes artigos da Convenção balizam o Comitê para instar seus Estados-Partes a adotarem as medidas apropriadas em todas as esferas políticas (inclusive legislativas) para garantir às mulheres o exercício e o gozo dos diretos humanos em igualdade de condições com o homem (Espino, 2010:33). Com esse pano de fundo, serão examinados aspectos relativos ao exercício dos direitos políticos das mulheres brasileiras, argentinas, chilenas $e$ costarriquenses, priorizando as observações do Comitê CEDAW encaminhadas aos países examinados. 


\section{Pactos pelos Direitos Políticos das Mulheres}

A assinatura e a ratificação de convenções internacionais $e$ de seus protocolos facultativos criaram condições para impulsionar, garantir e proteger os direitos das mulheres, incluindo os políticos. As "Constituições latino-americanas recentes conferem um status jurídico especial e diferenciado aos tratados de direitos humanos" (Piovesan, 2006:31). Em relação aos países examinados, a Constituição da Argentina (1994) atribui à CEDAW status de norma constitucional, a Carta da Costa Rica (2003) incorpora o mesmo preceito e vai além lhe aferindo caráter supraconstitucional (Beltrán, 2009). A Constituição brasileira (1988), por sua vez, acolhe os tratados de direitos humanos sem menção direta à Convenção. Assim, entre as controvérsias na interpretação da hierarquia dos tratados a tendência é a Convenção ser igualada às leis do país. No Chile (1989), essa situação é indefinida, haja vista que a Carta Magna do país está por ser refeita e o Protocolo Facultativo à Convenção, firmado em 1999, aguarda ratificação. $\mathrm{O}$ Quadro 1 registra o ano de assinatura e de ratificação da Convenção e de seu Protocolo.

\section{Quadro 1 - Adesão à CEDAW}

\begin{tabular}{|l|c|c|c|c|}
\hline \multirow{2}{*}{ Países } & \multicolumn{2}{|c|}{ Convenção CEDAW } & \multicolumn{2}{c|}{ Protocolo Facultativo } \\
\cline { 2 - 5 } & Assinatura & Ratificação & Assinatura & Ratificação \\
\hline Argentina & 1980 & 1985 & 2000 & 2006 \\
\hline Costa Rica & 1980 & 1986 & 1999 & 2001 \\
\hline Chile & 1980 & 1989 & 1999 & -- \\
\hline Brasil & 1981 & 1984 & 2001 & 2002 \\
\hline
\end{tabular}

Fonte: Elaboração própria a partir de

$<$ http://www.un.org/womenwatch/daw/cedaw/sigop.htm $>$.

O conteúdo do Quadro 1 denota a pronta adesão dos quatro países quando à assinatura dos mecanismos. Esse ocorrido corrobora a atribuição feita à América Latina de ter sido a região que mais cedo e, por unanimidade, aderiu à Convenção da 
Mulher e ao seu Protocolo Facultativo (Donoso; Valdés, 2007). A mesma agilidade, porém, não é verificada quando se trata de ratificar a Convenção. Mais demorado ainda é o processo de por em prática esse instrumento. Para ilustrar, o Brasil ratificou a Convenção em 1984 e somente em 2003 fez a primeira prestação de contas ao Comitê de especialistas, um ano após ter ratificar o Protocolo Facultativo à CEDAW. Na ocasião, entregou cinco relatórios periódicos combinados; em 2007, apresentou o sexto relatório e, em 2012, o sétimo. Independente disso é notória a importância da Convenção como expressão universal dos direitos humanos das mulheres, da igualdade $e$ da não discriminação em cada um dos países examinados (Donoso; Valdés, 2007; Pimentel, 2008).

No contexto dos mesmos países não foi visto sem surpresa o fato de a partir do segundo quinquênio dos anos 2000 terem sido eleitas quatro Presidentas para o exercício de mandatos quase simultâneos: Michelle Bachelet, no Chile (2006-10); Cristina Kirchner, na Argentina (2007-11); Laura Chinchilla, na Costa Rica (2010-14); e Dilma Rousseff, no Brasil (2011-15). Somado a isso, a presidenta Argentina foi reeleita, em 2011, e a chilena eleita mais uma vez para governar o país, em 2014. Ademais, a Presidenta brasileira também concorre à reeleição no pleito de 2014.

Em relação ao cenário adiante examinado, tem-se o seguinte panorama: Argentina e Costa Rica entre os países com índices mais elevados de representação parlamentar feminina da América Latina e em âmbito global; a Argentina liderou o uso do sistema de cotas (1991); a Costa Rica, foi uma das pioneiras em substituir as cotas, implantadas em 1996, pela paridade (2009) (Lhanos, 2013). Em contrapartida, o Brasil e o Chile situam-se entre os países com os piores índices de empoderamento político feminino (Gúzman, Moreno, 2007; Tobar et al, 2008). O primeiro com eleições sob o sistema de cotas desde 1996, e o segundo desde 1992 levantando a discussão a respeito das cotas. Destarte com a possibilidade de as cotas serem aprovadas no segundo mandato da Presidenta Bachelet. O Quadro 2 apresenta alguns elementos do cenário apontado. 
180 Mulheres, direitos políticos, gênero e feminismo

\section{Quadro 2 - Classificação em ranking mundial entre 142 países}

(set./2013)

\begin{tabular}{|c|l|c|c|c|c|c|c|c|}
\hline & & \multicolumn{3}{|c|}{ Câmara Baixa ou Única } & & \multicolumn{3}{|c|}{ Câmara Alta } \\
\hline $\begin{array}{c}\text { Rank } \\
\text { IPU }\end{array}$ & Países & Eleição & Vagas & Deputadas & $\%$ & Vagas & Senadoras & $\%$ \\
\hline 15 & $\begin{array}{l}\text { Costa } \\
\text { Rica }\end{array}$ & 2010 & 57 & 22 & 38.6 & - & - & - \\
\hline 18 & Argentina & 2011 & 257 & 96 & 37.4 & 72 & 28 & 38.9 \\
\hline 94 & Chile & 2009 & 120 & 17 & 14.2 & 38 & 5 & 13.2 \\
\hline 121 & Brasil & 2010 & 513 & 44 & 8.6 & 81 & 13 & 16.0 \\
\hline
\end{tabular}

Fonte: Women in national parliaments $-<$ http://www.ipu.org/wmne/arc/classif010913.htm>.

A Costa Rica e a Argentina situam-se entre os países com índices mais elevados de representação parlamentar em escala mundial. Segundo dados da União Interparlamentar, de setembro de 2013, a Costa Rica ocupava o 15 lugar em um ranking de 142 países e a Argentina a posição de número 18. No mesmo escrutínio, o Chile aparece no $94^{\circ}$ lugar, enquanto o Brasil fica na posição 121 (Quadro 2). Em termos percentuais e consideradas as câmaras alta e baixa combinadas, Argentina (sistema bicameral) $e$ Costa Rica (sistema unicameral) ficam em vantagem em relação às médias mundial $(21,7 \%)$ e regional (24,9\%), enquanto Brasil e Chile permanecem muito aquém desses resultados (IPU, 2013).

Consoante ao Brasil, o debate sobre os direitos políticos das mulheres é oportuno no contexto das eleições de 2014, vez que a comemoração dos 82 anos de conquista do direito de voto feminino no país vem acompanhada de um quadro parlamentar no qual a representação política das brasileiras permanece estagnada. Nesse sentido, perdendo posições em comparação ao restante do mundo e aos seus vizinhos da América Latina (Araújo, 2010).

Com efeito, é preciso ter presentes os desafios para harmonizar as legislações nacionais e traduzi-las em mudanças efetivas na prática política de cada país. As manifestações do Comitê CEDAW evidenciam as dificuldades das mulheres para o logro efetivo da tutela de seus direitos políticos. A fim de avaliar, 
nesse sentido, a realidade em cada país, o Comitê se baseia em artigos da Convenção e em recomendações gerais. As últimas, fruto da interlocução do Comitê com agentes nacionais $e$ internacionais, vêm sendo elaboradas desde a aprovação da CEDAW (1979) com o intuito de atualizar o tratado e, ao mesmo tempo, facilitar e garantir a sua aplicação pelos Estados-Partes.

No monitoramento sobre os direitos políticos das mulheres, o Comitê se orienta, especificamente, por duas recomendações gerais $(23$ e 25) e pelo disposto nos artigos 7 e 8 , relativos à participação na vida pública e política, somando a esses $01^{\circ}$ parágrafo do artigo 4, sobre cotas, e o artigo 5 , sobre estereótipos e padrões culturais. A Recomendação Geral 23, de 1997, a mais detalhada de todas, recupera antecedentes históricos e normativos de outros instrumentos de proteção aos direitos humanos das mulheres sobre participação política. Já a Recomendação Geral 25 , de 2004, estabelece os critérios para a adoção de "medidas especiais", consoantes ao artigo 4 (parágrafo 1), abarcando uma gama de instrumentos, políticas e práticas voltados a promover o avanço das mulheres em espaços de poder e decisão.

Tendo isso em vista e com a preocupação de começar a explorar algumas nuances da relação gênero e política em países governados por mulheres, são expostas $e$ examinadas as Observações Finais do Comitê CEDAW sobre a participação das mulheres na vida pública e política de cada um dos países em estudo. Para tal, a disposição dos países obedece a seguinte ordem: Argentina, Costa Rica, Chile e Brasil. Esse ordenamento foi adotado com a finalidade de apresentar desde as observações específicas do Comitê até as mais contundentes. 
182 Mulheres, direitos políticos, gênero e feminismo

\section{Observações e Recomendações específicas do Comitê CEDAW ${ }^{2}$}

Argentina - O Comitê examinou o sexto informe periódico da Argentina em julho de 2010, entre os dias 12 e 30, durante o $46^{\circ}$ período de sessões.

Participação na vida política e pública

Parágrafo 31. O Comitê celebra o aumento notável do número de mulheres na política, a eleição da primeira mulher Presidenta do país, que, tomadas em conjunto, as candidatas à presidência obtiveram mais de $78 \%$ dos votos emitidos, que um quarto dos ministérios é dirigido por mulheres e que, no momento atual [2010], 22\% dos secretários do Poder Executivo Nacional e 23\% dos subsecretários sejam mulheres. Observa que numerosas mulheres ocupam postos superiores ou executivos em outras instituições e organismos da administração nacional ou das administrações provinciais, tanto no poder legislativo nacional como em algumas legislaturas provinciais, no judiciário e, em certa medida, no setor privado. Entretanto, o Comitê observa diferenças entre as distintas províncias (CEDAW/C/ARG/6, 2010).

Parágrafo 32. O Comitê convida o Estado-Parte a resolver a grande disparidade entre as distintas províncias no que se refere ao grau de participação e representação política das mulheres, em particular investindo em campanhas de educação e sensibilização orientadas a eliminar os obstáculos sociais imperantes e desmontar as atitudes e estereótipos sexistas predominantes em algumas regióes (CEDAW/C/ARG/6, 2010).

No sentido das avaliações do Comitê, distintos estudos demonstram a falta de homogeneidade quanto à distribuição da

${ }^{2}$ As Observações Finais referentes aos países examinados e demais signatários da Convenção estão disponíveis no site da Division for the Advancement of Women, em <www.un.org/womenwatch/daw/>. 
representação feminina no território argentino. Essa disparidade é ressaltada por Nélida Archenti ao destacar o padrão desigual da presença política feminina nas províncias do país. Segundo ela:

\begin{abstract}
Ainda que no Congresso da nação Argentina tenham sido apresentados projetos de lei para substituir o sistema de cotas de gênero por um sistema paritário, a necessidade de paridade em nível nacional todavia não foi instalada nas agendas parlamentares e públicas neste país (Archenti, 2014:320).
\end{abstract}

Situação semelhante se verifica na Costa Rica, com uma representação muito próxima da Argentina - ambas, como dito antes, situadas entre os países com maior representação parlamentar feminina na América Latina e, também, em relação à boa parte da Europa. Em relação à Argentina que adota essa medida em algumas de suas províncias, a Costa Rica é um dos quatro países da região em que vigora a lei da paridade, adotada em 2009, porém com sua aplicação para o território nacional apenas a partir $\mathrm{n}$ das eleições de 2014. Portanto, a avaliação do Comitê capta apenas o início desse processo da paridade.

Costa Rica - O Comitê examinou dois informes periódicos combinados da Costa Rica - quinto e sexto - em julho de 2011, no $49^{\circ}$ período de sessões.

Participação na vida política e pública

Parágrafo 24. O Comitê observa com satisfação a alteração do Código Eleitoral (2009), que mudou o sistema de cotas para a participação da mulher na vida política a um sistema orientado à paridade entre os gêneros $(50 \%$ de mulheres $e$ $50 \%$ de homens). Sem embargo, preocupa o Comitê que a emenda se aplique apenas aos cargos eletivos do sistema de representação proporcional (postos na Assembleia Nacional) e não aos cargos eletivos do sistema de maioria (cargos executivos), utilizado para a maior parte dos postos importantes com faculdades decisórias. O Comitê também 
184 Mulheres, direitos políticos, gênero e feminismo

observa com preocupação que não foram adotadas medidas especiais de carácter temporário para garantir a participação na vida política e pública dos grupos desfavorecidos de mulheres, como as mulheres com deficiências, as indígenas $e$ as de ascendência africana (CEDAW/C/CRI/5-6, 2011).

\section{Parágrafo 25. O Comitê recomenda ao Estado parte que:}

a) Considere a possibilidade de modificar novamente o Código Eleitoral com o fim de assegurar a aplicação da paridade entre os gêneros nos cargos eletivos sob o sistema de representação majoritária, em consonância com a resolução nº. 3671-E8-2010 do Tribunal Superior Eleitoral;

b) Aplique, quando necessário, medidas especiais de caráter temporário, em conformidade com o parágrafo 1 do artigo 4 da Convenção e da recomendação geral 25 do Comitê, a fim de acelerar a participação plena e igualitária das mulheres na vida pública e política, em particular com respeito aos grupos desfavorecidos de mulheres, como as mulheres com deficiência, as mulheres indígenas $e$ as mulheres de ascendência africana (CEDAW/C/CRI/5-6, 2011).

A experiência da Costa Rica com o uso das cotas e da paridade/alternância revela o problema da aplicação desses mecanismos nos cargos unipessoais (sistema majoritário), porquanto a tendência partidária é a de postular candidaturas masculinas para os primeiros lugares das listas de votação tendência mantida nas eleições de 2010. Outra matéria pendente, como observa Isabel Garcia, é o fato de a lei da paridade/alternância não garantir a representação da diversidade étnica ou racial entre um mesmo sexo (Torres García, 2013:193). Oportuno observar, seguindo a autora, que essas situações fazem parte das preocupações do Comitê CEDAW endereçadas ao Estado da Costa Rica. Nesse sentido, na medida em que o Comitê felicita o avanço quanto à ampliação da garantia dos direitos políticos das mulheres em igualdade e não discriminação, ele também recomenda a adoção de ações para o seu fortalecimento. 
Chile $^{3}$ - O Comitê examinou o quinto e o sexto relatórios periódicos combinados do Chile em outubro de 2012, entre os dias $1^{\circ}$ e 19 no $53^{\circ}$ período de sessões.

\section{Participação na vida política e pública}

Parágrafo 24. Elogia o empenho do Estado-Parte para reforçar a liderança política da mulher mediante $\mathrm{o}$ estabelecimento do Programa "600 mulheres líderes para o Chile", preocupa o Comitê o escasso número de mulheres no Governo, nas duas Câmaras do Parlamento, no serviço diplomático, no judiciário e no desempenho de funções de prefeitas e vereadoras. O Comitê lamenta que a persistência de atitudes e estereótipos patriarcais e a falta de medidas especiais de caráter temporário sigam dificultando a participação das mulheres, incluídas as mulheres indígenas, no parlamento e nos cargos de responsabilidade em nível estatal e municipal. Ademais, o Comitê reitera sua preocupação pelo fato de o sistema eleitoral binominal resultar desfavorável à representação política da mulher (CEDAW/C/CHI/CO/5-6, 2012).

\section{Parágrafo 25. O Comitê incita o Estado parte a que:}

a) Considere a adoção, quando necessário, de medidas especiais de caráter temporário, a fim de acelerar a participação plena e igualitária da mulher na vida pública $e$ política;

b) Redobre os esforços encaminhados a aumentar a participação das mulheres na vida política em níveis nacional e municipal, incluindo a realização de campanhas de sensibilização oferecendo incentivos para que os partidos políticos indiquem um número igual de mulheres $e$ homens nas candidaturas $e$ financiem adequadamente as campanhas das candidatas;

3 Uma avaliação sobre todos os temas abordados pelo Comitê CEDAW em relação ao caso chileno pode ser encontrada em Valdés (2013). 
186 Mulheres, direitos políticos, gênero e feminismo

c) Adote todas as medidas necessárias para iniciar a reforma do sistema eleitoral binominal (CEDAW/C/CHI/CO/5-6, 2012, grifo no original).

Quanto às recomendações do Comitê sobre participação política, as duas primeiras ( $\mathrm{a}$ e b) deverão ser revisadas em um prazo de dois anos, e não em quatro como de costume, para a apresentação dos relatórios oficiais dos países. Sobre a recomendação referente ao sistema binomial, vale notar que Michele Bachelet, logo após tomar posse na Presidência do Chile em 2014, encaminhou a proposta de substituição desse sistema por um sistema proporcional, na qual foi incluído o estabelecimento de um sistema de cotas para que pelos menos $40 \%$ das candidaturas ao Congresso sejam de mulheres.

Ainda sobre o caso chileno, importa registrar a análise de Teresa Valdés na qual contemplou o conjunto de observações e recomendações do Comitê CEDAW ao Chile em 2012. Segundo ela, as manifestações do Comitê quando vistas como um todo,

[...] mostram um país marcado por graves desigualdades sociais e a discriminação por gênero, com uma democracia deficitária em termos de participação e representação e com enclaves conservadores e autoritários que ainda não reconhecem os objetivos da Convenção (Valdés, 2013:181).

Concluindo a exposição sobre as avaliações do Comitê CEDAW, enfocam-se as manifestações desse órgão dirigidas ao governo brasileiro. Referente a esse processo, cabe mencionar que nas três ocasiões em que o Brasil prestou contas sobre a aplicação da Convenção (2003, 2007 e 2012) a exclusão política das mulheres aparece elencada no documento "Observações Finais" (Concluding Comments), entre as "Principais esferas de preocupação e recomendações" do Comitê.

Brasil - O Comitê examinou o sétimo relatório periódico do Brasil em 2012, entre os dias 13 de fevereiro e 2 de março de 2012, no $51^{\circ}$ período de sessões. 
Participação na vida política e pública

Parágrafo 4. O Comitê saúda a eleição da Sra. Dilma Rousseff como a primeira mulher presidenta do Brasil, em outubro de 2010, assim como a nomeação de 10 mulheres ministras (CEDAW/C/BRA/7, 2012).

Parágrafo 22. O Comitê destaca os esforços do EstadoParte para aumentar a participação das mulheres na vida política e pública, como, por exemplo, a adoção da Lei $n^{\circ}$ $12034 / 2009$, que exige que os partidos mantenham uma representação mínima de $30 \%$ e máxima de $70 \%$ de homens ou mulheres em suas listas de candidatos $e$ o lançamento das campanhas permanentes "Mais Mulheres no Poder", em 2008. No entanto, lamenta que a persistência de atitudes e estereótipos patriarcais, bem como a falta de mecanismos para garantir a implementação de medidas especiais temporárias continuem a impedir a participação das mulheres no legislativo e em cargos de tomada de decisão nos âmbitos estadual e municipal da administração pública. Inquieta também a baixa representação das mulheres nas mais altas instâncias do Judiciário e nas posições de alta gestão no setor privado, apesar do número crescente de mulheres seguindo carreira no Judiciário, assim como participando do mercado de trabalho (CEDAW/C/BRA/7, 2012).

\section{Parágrafo 23. O Comitê insta o Estado-parte:}

a) Intensificar seus esforços para alterar ou adotar legislação visando a aumentar a participação de fato das mulheres na vida política e prosseguir nas políticas sustentadas que visam à participação plena e igualitária das mulheres na tomada de decisões, como uma exigência democrática em todas as áreas da vida pública, política e profissional, utilizando recomendação geral do Comitê $n^{\circ} 23$ (1997) sobre as mulheres na vida pública;

b) Adotar e garantir a implementação de medidas especiais temporárias, de acordo com o artigo 4, parágrafo 1 , da Convenção e a Recomendação Geral nº 25 (2004), a fim de 
acelerar a plena e igual participação das mulheres na vida pública e política, mormente no que diz respeito aos grupos de mulheres em desvantagem, como as afrodescendentes, indígenas e mulheres com deficiência; $e$

c) Realizar campanhas de conscientização, visando a homens e mulheres, para eliminar atitudes patriarcais $e$ estereótipos sobre os papéis de homens e mulheres, destacando a importância da participação plena e igual das mulheres na vida política e pública e nas posições de tomada de decisão nos setores público e privado e em todas as áreas (CEDAW/C/BRA/7, 2012).

As preocupações nomeadas pelo Comitê em relação ao Brasil (Parágrafo 22) servem para retomar aspectos da relação gênero e política tratados neste artigo. Também permitem dimensionar a fragilidade de dispositivos legais como o do sistema de cotas. Associado a isso, aparece o problema dos déficits de participação e representação política das mulheres, pertinente, também, ao caso chileno. No plano das recomendações (Parágrafo 23) encaminhadas ao Brasil, os posicionamentos do Comitê afiançam as reflexões de gênero sobre o impacto de fatores de ordem cultural e institucional no fenômeno da sub-representação política das mulheres.

Saliente-se, nesse sentido, a alusão à Recomendação Geral $n^{\circ} 23$ encaminhada ao Brasil quando é sugerida a definição de prazo concreto para aumentar o número de mulheres em cargos públicos e políticos. Essa Recomendação, voltada à inserção das mulheres na vida pública e política, "recupera os antecedentes políticos e normativos da construção dos direitos humanos das mulheres sobre participação política" (Pimentel, 2008:48-49). Para tanto, vale-se do artigo $4^{\circ}$ da Convenção que requer a adoção de medidas especiais (cotas de gênero) para acelerar a igualdade de fato entre o homem e a mulher, e o artigo $5^{\circ}$ (inciso $a$ ), que demanda a modificação de padrões socioculturais e a eliminação de estereótipos de gênero (Pimentel, 2008:48-49). Desse prisma, a discriminação política de gênero é abordada a partir da incidência de fatores normativos e culturais, com ênfase nos últimos. 
Como referem Nélida Archenti e Maria Inês Tula (2008:15), a presença de traços patriarcais na cultura política latinoamericana $e$ a sua predominância em relação à identidade de gênero "incidem negativamente na efetividade das cotas para mulheres na política". Tais traços, dizem as autoras, vão estar presentes em várias circunstâncias de aplicação do sistema de cotas e podem encontrar correspondência em costumes e normas informais, em práticas partidárias e seus graus de democratização, ou na dinâmica interna de cada agremiação política.

$\mathrm{O}$ aporte da dimensão cultural pode ser sintetizado pela manifestação sobre a falta ou a falha de medidas legais (lei de cotas) para potencializar a representatividade política feminina. Resulta daí a recomendação do Comitê para que os governos brasileiro e chileno conjuguem leis a campanhas de conscientização sobre a importância da inclusão política das mulheres, entendendo-a intrínseca a uma sociedade democrática. Também sobre as cotas, verifica-se a recorrência do tema na avaliação de outros relatórios chilenos e brasileiros.

Ainda em relação ao Brasil, as manifestações do Comitê eram esperadas, vez que a revisão do dispositivo das cotas, firmada na Lei $\mathrm{n}^{\circ} 12.034$, da minirreforma política de 2009, mostrou-se insuficiente para incidir minimamente sobre a ausência das mulheres em esferas de poder e decisão. Situação evidente quando se consideram estatísticas parlamentares e os baixos índices de empoderamento político feminino (Prá, 2011). Portanto, em relação às brasileiras $e$ às chilenas fica em aberto o compromisso de seus países no enfrentamento ao problema da sub-representação das mulheres na política. Em contrapartida, nos casos das argentinas $e$ costarriquenses o desafio é sustentar o já conquistado.

A garantia institucional do direito de voto e de participação nas esferas de poder (cotas e paridade) convive com elementos patriarcais na cultura política que, relacionados a déficits em sistemas políticos, eleitorais e partidários, incidem restritivamente, no acesso das mulheres a cargos eletivos e à vida pública (CIDH, 2011). Na leitura de Line Bareiro isso evidencia porque "os questionamentos feministas sobre a estruturação patriarcal do 
poder não se circunscrevem à política e ao Estado" (Bareiro, 2000:25). Antes disso, diz ela, "propõem a profunda e radical transformação cultural na sociedade e no conjunto das instituições incluindo, por certo, a família" (Bareiro, 2000:25). Questões dessa ordem, como visto antes, subsidiam incursões feministas a outros centros de poder e dotam suas propostas e iniciativas de um caráter internacional.

Apesar dos desafios, é inegável o protagonismo das mulheres na definição da pauta de agendas públicas $e$ governamentais. Pautas que se associam a uma agenda internacional $e$ a recomendações (acordos e documentos) pactuadas em eventos chancelados pelas Nações Unidas. Em suma, as mulheres encontram-se diante de uma experiência de mobilização nacional $e$ internacional que amplia espaços de participação e representação política $e$ imprime novos formatos no desenho das políticas públicas. Não obstante, tal realidade também requer enfrentar novos dilemas.

\section{Considerações finais}

Neste artigo, buscou-se compreender e explicar os déficits de participação e de representação política feminina à luz das teorias feministas e dos estudos de gênero. As tensões ou os paradoxos à expansão da cidadania política das mulheres foram sintetizados com o intuito de situar as questões de gênero no marco da análise política. Para tal, se teve em vista a centralidade da ingerência política das mulheres na afirmação da igualdade política de gênero. O debate arrolado envolveu reflexões teóricas e os discursos feministas sobre os direitos políticos das mulheres, tendo em vista as manifestações do Comitê CEDAW aos quatro países examinados.

$\mathrm{O}$ artigo apresentou um panorama sobre a questão dos direitos políticos das mulheres, aludindo à realidade da relação gênero e política. Com essa referência, foram enfocadas as interpelações democráticas voltadas a eliminar as barreiras à concretização daqueles direitos. Interpelações provenientes de 
uma agenda de expansão da cidadania feminina e dos direitos humanos das mulheres - em suma, orientada à igualdade de gênero. Dessas, priorizaram-se avaliações sobre a situação política das mulheres, com atenção aos comentários conclusivos $e$ as recomendações do Comitê CEDAW. Nesse trajeto se fez referência à Convenção como um "programa de ação pública para eliminar a discriminação contra as mulheres e lograr a igualdade formal $e$ substantiva entre mulheres e homens" (Valdés, 2013:171).

Com o subsídio de estudos e pesquisas sobre gênero $e$ política e pelo exame das manifestações do Comitê CEDAW foi possível incursionar no cenário da participação e da representação política de países como Brasil, Chile, Argentina e Costa Rica. O processo de reconhecimento dos direitos políticos das mulheres nos países examinados, ressalvadas diferenças de normas e resultados, pode ser considerado lento e inacabado. Ademais, para além dos problemas encontrados em países como a Argentina e Costa Rica, os casos brasileiro e chileno evidenciam a urgência de superar o patamar de sub-representação política feminina.

O exercício de abordar comparativamente a questão dos direitos políticos das mulheres permitiu evidenciar a manutenção da distância entre os direitos cunhados em instrumentos internacionais, os quais os Estados têm obrigação de cumprir, e a concretização desses direitos. Igualmente, ficou evidenciado o fato de o aumento da liderança política feminina na região não expressar a realidade dos direitos políticos das mulheres em outras instâncias de poder (do Executivo, do Legislativo, do Judiciário ou partidos políticos). Portanto, ainda se está distante da igualdade preconizada por organizações feministas e de mulheres ou pelos mecanismos de defesa dos direitos humanos das mulheres. Nesse âmbito, a real participação e a representação política feminina em todas as esferas políticas seguem identificadas desde os feminismos como condição necessária ao fortalecimento democrático, o que é almejado com a defesa da democracia paritária.

Nomeadamente, desde a luta pelo direito ao voto, as organizações feministas e de mulheres seguem partilhando experiências de mobilização nacional, regional e internacional. Por 
esses caminhos as mulheres ampliam seus espaços de participação e qualificam os conteúdos da agenda pública com o debate e a prática da democracia paritária. Por conseguinte, na medida em que as mulheres questionam os princípios da democracia moderna e os déficits de seus direitos políticos abrem um amplo campo de ação política e reposicionam na agenda feminista uma extensa pauta de pesquisa.

\section{Referências bibliográficas}

AmÂNCIO, Lígia. Masculino e feminino. A construção social da diferença. Lisboa: Afrontamento, 1994.

ARAUJO, Clara. Rotas de ingresso, trajetórias e acesso das mulheres ao legislativo: um estudo comparado entre Brasil e Argentina. Revista Estudos Feministas vol.18, n² 2 , Florianópolis-SC, UFSC, 2010, pp.567-584.

ARCHENTI, Nélida; TULA, María Inés. Algunas cuestiones iniciales sobre las leyes de cuotas. In: ARCHENTI, N.; TULA, M. I. (eds.). Mujeres y política en América Latina: Sistemas electorales y cuotas de género. Buenos Aires, Heliasta, 2008, pp.9-29.

ARCHENTI, Nélida. El proceso hacia la paridad en América Latina. Argentina y Costa Rica, experiencias comparadas. Revista Digital de Derecho Electoral n¹7, San José, Costa Rica, Tribunal Supremo de Elecciones, enero-junio, 2014, pp.304-332. Disponível em: $<$ http://www.tse.go.cr/revista/revista,htm. $>$.

BAREIRO, Line. El Estado, las mujeres y la política a través de la historia latinoamericana. In: Memoria Del II Seminario Regional. De poderes y saberes. Debates sobre reestructura politica y transformación social. Montevideo, Doble clic ed./DAWN/REPEM, 2000, pp.11-32.

BAREIRO Line; DE SOTO, Clyde; SOTO Lilian. La inclusión de las mujeres en los procesos de reforma política en América Latina, Banco Interamericano de Desarrollo, Departamento de Desarrollo Sostenible, Unidad para la Igualdad de Género en el Desarrollo, marzo 2007. Disponível em: $<w w w . i a d . o r g / s d s / d o c /$ prolead_MujeresReformaPol.pdf $>$. 
BAREIRO, Line; TORRES, Isabel (eds.). Igualdad para una democracia incluyente.Instituto interamericano de Derechos Humanos. San José, C.R., IIDH, 2009.

BELTRÁn, María José Lubertino. Las leyes de cuotas en la experiencia latinoamericana. In: BAREIRO, Line; TORRES, Isabel (eds.). Igualdad para una democracia incluyente. Instituto interamericano de Derechos Humanos. San José, C.R., IIDH, 2009, pp.85-157.

CEDAW. Observaciones finales sobre el sexto informe periódico de Argentina, adoptadas por el Comité en su $46^{\circ}$ período de sesiones (12 a 30 de julio de 2010) (CEDAW/C/ARG/6), 13 de julio de 2010. Disponível em: $<$ http://www.acnur.org/t3/fileadmin/Documentos/BDL/2012/8408.pdf>

CEDAW. Observaciones finales sobre los informes periódicos quinto y sexto de Costa Rica, adoptadas por el Comité en su $49^{\circ}$ período de sesiones (11 a 29 de julio de 2011) (CEDAW/C/CRI/5-6), 11 de julio de 2011. Disponível em: <http://www.acnur.org/t3/fileadmin/Documentos/BDL/2012/8421.pdf>.

CEDAW. Observaciones finales sobre el séptimo informe periódico de Brasil, adoptadas por el Comité en su $51^{\circ}$ período de sesiones (13 de febrero a 2 de marzo de 2012) (CEDAW/C/BRA/7), 17 de febrero de 2012. Disponivel em: <http://www.acnudh.org/wpcontent/uploads/2012/03/CEDAW-Brasil-2012-Esp.pdf $>$.

CEDAW. Observaciones finales sobre los informes periódicos quinto y sexto de Chile, adoptadas por el Comité en su $53^{\circ}$ período de sesiones $\left(1^{\circ}\right.$ a 19 de octubre de 2012) (CEDAW/C/CHL/CO/5-6), 12 de noviembre de 2012a. Disponível em: <http://acnudh.org/wpcontent/uploads/2013/01/CEDAW-Chile-2012-ESP.pdf > .

CEPAL. El aporte de las mujeres a la igualdad en América Latina y el Caribe. X Conferencia Regional sobre la Mujer de América Latina y el Caribe. Quito, Ecuador, 6 al 9 de agosto, 2008.

CIDH - Comisión Interamericana de Derechos Humanos. El camino hacia una democracia sustantiva: la participación de las mujeres en las Américas. OEA/Ser.L/V/II. Doc.79, abril, 2011.

Cово, Rosa. Democracia paritaria y sujeto político feminista. Anales de la Cátedra de Francisco Suárez, nº 36, 2001, pp.29-44. 
194 Mulheres, direitos políticos, gênero e feminismo

DAHLERUP, Drude. De uma pequena a uma grande minoria: uma teoria da "massa crítica" aplicada ao caso das mulheres na política escandinava. In: LAMAS, Marta (org.). Debate feminista: cidadania e feminismo. São Paulo, Melhoramentos, 1999, pp.142-183.

DONOSO; VALDÉS, Teresa. La participación política de las mujeresen América Latina. Informe Regional. Chile, ALOP/CEDEM, 2007.

DURÁN, Paloma. Las Naciones Unidas y la igualdad de oportunidades entre mujeres y hombres. Nova York, INSTRAW, 2005.

ESPINO, Adriana Medina. La participación política de las mujeres. De las cuotas de género a la paridad. México, Centro de Estudios para el Adelanto de las Mujeres y la Equidad de Género/Cámara de Diputados. LXI Legislatura, 2010.

FACIO, Alda. Feminismo, género y patriarcado. In: FRIES, Lorena; FACIO, Alda (eds.). Género y Derecho. Santiago de Chile, LOM Ediciones, La Morada, 1999.

GuZMÁN, Virginia; MoRENO Claudia. Hacia un horizonte paritario en América Latina: representación política de las mujeres. Santiago de Chile, Comisión Económica para América Latina y el Caribe (CEPAL), 2007.

IPU - Inter-Parliamentary Union. Women in national parliaments: situation as of 31 September 2013 - World Classification. Disponivel em: $<$ http://www.ipu.org/wmn-e/world.htm $>$.

LAVAlle, Cecilia Torres. Paridad es la meta: mujeres en los ayuntamientos de Quintana Roo, 1975-2010. México, Instituto Nacional de las Mujeres; Instituto Quintanarroense de la Mujer, 2010.

LLANOS, Beatriz Cabanillas. A modo de introducción: caminos recorridos por la paridad en el mundo. In: IDEA/OEA/CIM. La apuesta por la paridad: democratizando el sistema político en América Latina. Los casos de Ecuador, Bolivia y Costa Rica. Perú, IDEA Internacional/ CIM Comisión Interamericana de Mujeres, 2013, pp.17-46.

LlanOS, Beatriz Cabanillas. Participación política de las mujeres de América de Sur "En busca de la paridad". Foro Internacional de Mujeres Líderes de América del Sur y Países Árabes, 2014.

PIMENTEL, Silvia. Experiências e desafios: comitê sobre a eliminação de todas as formas de discriminação contra a mulher (CEDAW/ONU) - 
relatório bienal de minha participação. Brasília, Secretaria Especial de Políticas para as Mulheres, 2008. (Série Documentos).

PIMENTEL, Silvia. El rol de la CEDAW en la construcción de la ciudadanía de las mujeres. In: Inter-American Commission of Women. La democracia de ciudadanía: Visiones y debates desde los derechos de las mujeres en las Américas /Comisión Interamericana de Mujeres, Organización de los Estados Americanos, 2012, pp.145-161

PIOVESAN, Flávia. Direitos humanos e o Direito Constitucional Internacional. Caderno de Direito Constitucional. Módulo V. Escola da Magistratura do Tribunal Regional Federal da $4^{a}$ Região, Porto Alegre-RS, EMAGIS, 2006.

PITANGUY, Jacqueline; MIRANDA, Dayse. As mulheres e os direitos humanos. In: PUGLIA, June (coord.). O progresso das mulheres no Brasil. Brasília, UNIFEM, 2006, pp.14-31.

PRÁ, Jussara Reis. Reflexões sobre gênero, mulheres e política. In: Paiva, Denise (org.). Mulheres, política e poder. Goiânia, Editora da UFG, 2011, pp.101-126.

PULEO, Alicia H. Filosofia e gênero: da memória do passado ao projeto de futuro. In: GodinHo, Tatau; SiLverRA, Maria Lúcia da (orgs.). Políticas Públicas e Igualdade de Gênero. São Paulo, Coordenadoria Especial da Mulher, 2004, pp.13-34.

SCOTT, Joan. Gênero: uma categoria útil de análise histórica. Educação e Sociedade, Porto Alegre, vol. 20, nº 2, jul./dez. 1990, pp.71-99.

SzWAKO, José. ¿Una interfaz internacional? Una comparación entre discursos feministas al rededor de la "Convention on the Elimination of All Forms of Discrimination against Women". Texto para presentación en el Congreso de la Latin American Studies Association (LASA) en Toronto, Canadá, de 6 a 9 de octubre del 2010.

TOBAR, Marcela Ríos; HormaZÁBAL, Daniela; COOK, Maggi. El efecto de las leyes de cuota en la representación de las mujeres en América Latina. In: TOBAR, Marcela Ríos (edit.). Mujer y política. El impacto de las cuotas de género en América Latina. Santiago, Chile, Catalonia, 2008, pp.221-242

TORRES GARCÍA, Isabel. Paridad para el fortalecimiento de la democracia incluyente: el caso de Costa Rica. In: IDEA/OEA/CIM. La apuesta por 
196 Mulheres, direitos políticos, gênero e feminismo

la paridad: democratizando el sistema político en América Latina. Peru, IDEA, 2013, pp.179-235.

VALDÉs, Teresa Echenique. La CEDAW y el Estado de Chile: viejas y nuevas deudas con la igualdad de género. Anuario de Derechos Humanos, n 9, 2013, pp.171-181.

VARELA, Nuria. Feminismo para principiantes. Barcelona, Ediciones B.S.A, 2014. 